\title{
A NECESSIDADE DE CRIAÇ̃̃O DE UM REGIME AMBIENTAL INTERNACIONAL: O CASO DOS DESLOCADOS AMBIENTAIS'
}

\author{
Profa. Dra. Andrea M. C. Pacheco Pacífico²
}

Sumário: 1 Introdução. 2 Regimes internacionais. 3 O Regime Internacional dos Refugiados e outros migrantes forçados. 4 Os deslocados ambientais. 5 Conclusões. Referências.

\begin{abstract}
Resumo: Um regime internacional é construído, primordialmente, por normas, regras e instituições que levam à promoção e à proteção do alvo do referido regime. Em se tratando de meio ambiente, a falta de um regime definido faz com que várias categorias populacionais fiquem ausentes de categorização jurídica e, assim, desprotegidas, tendo seus direitos humanos violados. Nessas situações estão os supostos refugiados ambientais e os deslocados internos ambientais, que são forçados a migrar por diversos fatores, embora a mudança ambiental ou climática seja o fator-chave. Esta pesquisa visa dar visibilidade a estes migrantes forçados, propondo medidas a ser tomadas pela sociedade e pelos governos, de modo que estes migrantes tenham seus direitos humanos protegidos, (e.g. direito à vida, à saúde, à educação, à segurança e ao desenvolvimento) e concretizados via cooperação entre os atores envolvidos.
\end{abstract}

Palavras-chave: deslocados ambientais; proteção jurídica; regime internacional.

\section{INTRODUÇÃO}

A relação entre os seres humanos e o meio ambiente é tão antiga quanto a humanidade. Entretanto, tempo e espaço mostram práticas e realidades singulares, de acordo com as necessidades e os recursos locais. Com as revoluções tecnológicas e de comunicação, é possível conhecer práticas diversas do passado e do presente e até prever o futuro, a fim de adaptar as necessidades humanas e a natureza à sustentabilidade. Esta pesquisa trata da relação entre os seres humanos e o meio ambiente e as consequências da falta de proteção a ambos.

O foco principal é mostrar a necessidade de proteger os deslocados forçados ambientais: ou categorizando-os como deslocados internos, conforme os Princípios Orientadores (1998) e a Declaração de San Jose (1994); ou aplicando os instrumentos de direitos humanos existentes; ou alongando o atual regime internacional dos refugiados e dos migrantes forçados em nível de implementação local, considerando as características da população e da terra locais; ou buscando criar um regime novo, por meio da persuasão via cruzamento de assuntos, resultante da colaboração entre população local, governo, instituições internacionais e ONG locais. Dessa forma, os deslocados forçados ambientais serão protegidos juridicamente em nível internacional, mesmo sem normas e instituições vinculantes

\footnotetext{
1 Artigo apresentado, originalmente no XXVIII Congresso Internacional da ALAS, entre 6 e 11/09/2011, Recife-PE, e publicado sucintamente na Revista Meridiano 47 (Boletim Meridiano 47, Brasília, Vol. 13, N. 133, ago. 2012).

2 Relações Internacionais/UEPB.
} 
que os protejam e aos seus direitos.

Longe de fornecer uma solução final ao dilema, ou seja, como a degradação ambiental, natural ou produzida/induzida pelo ser humano, leva ao deslocamento forçado e, consequentemente, a conflitos, rótulos, insegurança e ausência de proteção estatal, esta pesquisa define regimes internacionais, caracteriza o atual regime internacional dos refugiados e dos migrantes forçados, introduz a problemática dos deslocados forçados ambientais e elenca razões que justifiquem a criação de um regime internacional para eles, concluindo com sugestões possíveis de serem implementadas pelos Estados em nível local e que resultem emdesenvolvimento local, da terra e de seu povo.

\section{REGIMES INTERNACIONAIS}

Os regimes internacionais (ou, para Keohane e Young, instituições internacionais) se encontram inseridos no seio das teorias das relações internacionais, tendo sido popularizados nos anos 80 a partir da ideia de Keohane, apud Griffiths (2004, p.57-8), que os definiu como "variáveis a interferir no poder do Estado, de um lado, e nos resultados internacionais, do outro, de um mundo parcialmente globalizado." O que ocorreu foi que certos acontecimentos globais não puderam mais ser explicados pelos realistas e as organizações internacionais intergovernamentais (OI) falharam na gestão dos problemas e das questões globais, como a não previsão dos eventos que culminaram no fim da guerra fria.

A análise dos regimes internacionais veio preencher uma lacuna do sistema vigente, ou seja, um sistema, segundo Bull (2002), anárquico, sem autoridade central para tornar os tratados mais eficazes e de aplicação mais fácil, pois, embora as OI sejam instituições formais, com processos institucionais e destinadas a gerir bens comuns, os regimes são mais amplos, ou seja, eles são instituições internacionais, mas não são OI. Os regimes, muitas vezes, estão acompanhados de uma OI para colocá-los em prática, para responder pelos eventos ocorridos e para coletar e disseminar informações relativas ao campo de atuação deles, mas eles não são OI.

Assim, no início dos Anos 80, a Academia decidiu buscar uma definição precisa de regimes internacionais, cuja tentativa foi publicada no periódico “Organizações Internacionais”, que destinou um volume especial sobre o tema. Nesse diapasão, Krasner (1982, p. 185-6) os definiu como "um conjunto de princípios 
explícitos ou implícitos, normas, regras e procedimentos de tomada de decisões em que as expectativas dos atores convergem para uma dada área das Relações Internacionais."

Segundo ele, "as normas são padrões de comportamento definidos em termos de direitos e obrigações" e as "regras são prescrições ou proscrições específicas para a ação." Ele ainda define os "procedimentos de tomada de decisões como práticas que prevalecem para formular e implementar a escolha coletiva." Nesse sentido, ele afirma que os meios são as normas e os princípios, enquanto os fins são as regras e os procedimentos; e ambos são mutuamente constitutivos do resultado final, qual seja, os regimes internacionais.

Já Keohane definiu regimes internacionais como "instituições com regras explícitas, acordadas por governos, relativas a conjuntos específicos de questões nas relações internacionais." Segundo ele, as regras englobam as normas, as regras, os princípios e os procedimentos de tomada de decisões. Diferentemente de Keohane, para Krasner (1982, p. 188-9), o regime muda apenas se os princípios ou as regras mudarem, pois o resto são mudanças internas do regime e não do regime em si.

Para Young (1982, p. 277), "regimes são instituições sociais que governam as ações daqueles interessados em atividades específicas (ou conjunto de atividades aceitas). Como todas as instituições sociais, eles são padrões de comportamento ou práticas reconhecidas para os quais as expectativas convergem.”

Com as críticas recebidas por sua definição, Keohane, em 1993, trouxe uma nova definição de regimes internacionais, a saber: "acordos são termos puramente formais (regras explícitas acordadas por mais de um Estado) e regimes surgem quando os Estados reconhecem estes acordos como continuamente válidos." Para ele, um conjunto de regras não precisa ser efetiva para ser caracterizada como um regime, mas precisa ser reconhecida como de existência continuada. Assim, regimes são regras explícitas que se referem de forma positiva pelos governos, mesmo que eles não sejam necessariamente observados de forma escrupulosa.

O certo é que ainda não há consenso sobre as teorias dos regimes internacionais, embora seja claro que eles surgiram a partir das organizações internacionais intergovernamentais criadas para alcançar cooperação entre os Estados. Hasenclaver (1997), apud Barros-Paltiau, Varella e Schleicher (2004, p. 1112) distingue três correntes para explicar as teorias dos regimes internacionais, a saber: 
- A Realista ou estrutural analisa as relações de poder, pois sua distribuição entre os atores do sistema internacional influencia fortemente na possível formação e no declínio dos regimes internacionais. Ela liga regimes internacionais fortes à existência de um Estado dominante em certa área e busca explicar quando e porque os regimes internacionais emergem e são efetivos, no sentido de que os Estados seguem políticas de cooperação que, na falta de um regime, eles provavelmente seguirão. Mas, não hárobustês, pois se o Estado dominante desta estrutura unipolar cai, o regime se dissolve também, tornando-se não efetivo, como ocorre com a violação de normas e regras. Aqui, o poder é importante tanto para a coooperação quanto para o conflito entre os Estados, mas os Estados somente se preocupam com os ganhos (absolutos ou relativos), ou seja, a distribuição dos recursos de poder afeta fortemente a efetividade de um regime para emergir e se manter em certa área.

- A Neoliberal ou funcional analisa o conflito de interesses, ou seja, baseia-se fortemente na teoria microeconômica e é funcional porque o regime internacional surgiria para cumprir a tarefa de reduzir as incertezas entre os atores e fazê-los caminhar em direção a melhores resultados. Aqui, embora não sejam totalmente indiferentes aos efeitos das diferenças de poder, enfatiza-se o papel dos regimes internacionais em auxiliar os Estados a realizar seus interesses comuns, ou seja, os Estados são egoístas racionais que buscam somente seus ganhos absolutos. É o regime líder atual.

- A Cognitiva analisa a dinâmica do conhecimento, da comunicação e das identidades, com raízes na filosofia da ciência (como crítica ao racionalismo do homo economicus) e na sociologia (ao enfatizar questões de aprendizado, percepções e identidades de grupo). Aqui, são focadas as origens dos interesses como são percebidos pelos Estados e, assim, acentua-se o papel das ideias causais e normativas.

Um das grandes diferenças entre elas é o grau de institucionalismo que elas expoêm, ou seja, a extensão com que as instituições internacionais são efetivas ou não. Nesse sentido, um regime é efetivo se seus membros seguem as normas e as regras e se atingem certos de seus objetivos.

Outra diferença é o grau de robustês, ou seja, de resiliência dos regimes, que se refere à manutenção de poder das instituições internacionais em face dos desafios exógenos, além da extensão em que escolhas institucionais anteriores limitam as decisões coletivas e o comportamento posterior dos membros, ou seja, 
instituições mudam com a mudança de poder entre seus membros, quando os membros mais poderosos não possuem mais interesse na instituição ou o regime não lhe serve mais. O termo utilizado para isso é "perder robustês" ou "ser resiliente".

Destarte, os regimes internacionais surgem em razão da necessidade de cooperação, ou seja, de formação de um novo multilateralismo (Cox: 1996), de uma nova Ordem Mundial baseada na democratização. Segundo Wallerstein (1984 e 2002), a crise global demanda novos regimes e, mais ainda, um novo multiculturalismo, particularmente por que a teoria dos regimes se altera com as necessidades globais e regionais. Vários regimes internacionais nasceram como respostas positivas às necessidades globais de justiça e equidade e em virtude das falhas estatais, mas a partir das OI, que agem por meio da criação dos ditos regimes. Dentre os regimes atuais, podem-se citar o regime da não proliferação das armas nucleares, o regime do comércio internacional, o regime do meio ambiente, o regime dos direitos humanos e o regime dos refugiados. Falta, entretanto, um regime internacional que una migrantes forçado e meio ambiente, preenchendo a lacuna deixada pelo regime internacional dos refugiados.

\section{O REGIME INTERNACIONAL DOS REFUGIADOS E OUTROS MIGRANTES FORÇADOS}

$\mathrm{O}$ atual regime internacional dos refugiados (princípios, normas, regras e procedimentos de tomada de decisões) foi juridicamente criado em 1951, como uma resposta ao deslocamento forçado de pessoas após a Segunda Guerra Mundial, ou seja, ele deriva das consequências políticas e econômicas da Guerra para fornecer proteção àqueles que necessitam de segurança física e econômica e de bem estar social.

A Convenção de Genebra de 1951 relativa ao status de Refugiado (Convenção de 1951), em seu artigo $1^{\circ}$, e o Protocolo adicional de Nova Iorque de 1967 (Protocolo de 1967) definem refugiado como todo aquele que está fora de seu país de origem e não pode (ou não quer) a ele retornar devido a um temor bem fundado de perseguição em razão de raça, religião, nacionalidade, opinião política ou pertencimento a grupo social.

A Convenção de 1951 foi criada com o apoio do Escritório do Alto Comissiariado das Nações Unidas para os Refugiados (ACNUR), uma agência temporária da ONU que se tornou permanente devido ao crescimento interminável 
do número de refugiados no mundo. O ACNUR luta pela aplicação da definição de refugiado, pela implementação das soluções duráveis (integração local, repatriamento voluntário ou reassentamento em um terceiro país) e pela observância dos padrões de procedimento para determinar a condição jurídica de refugiado nos Estados acolhedores.

$\mathrm{O}$ atual regime dos refugiados é, claramente, um regime pronto e acabado, pois ele possui princípios, normas, regras e procedimentos de tomada de decisões. Dentre os princípios, há o non refoulement(não devolução forçada), em que um Estado não pode devolver um refugiado (ou solicitante de refúgio) ao Estado onde há perseguição ou temor bem fundado de perseguição ao indivíduo; a dignidade da pessoa humana, em que solicitantes de refúgio e refugiados possuem direitos humanos fundamentais assegurados nos locais de acolhimento; e o pacta sunt servanda, que visa dar segurança jurídica ao regime, já que não há um poder coercitivo superior e externo aos Estados que os obrigue a cumprir as normas previstas em tratados.

Importa mencionar, por exemplo, que, conforme Goodwin-Gill (2011), onon refoulement é uma norma imperativa de direito internacional geral (jus cogens) que, conforme o artigo 53 da Convenção de Viena sobre o Direito dos Tratados celebrados entre Estados (1969/80), é "uma norma aceita e reconhecida pela comunidade internacional dos Estados como um todo, como norma da qual nenhuma derrogação é permitida e que só pode ser modificada por norma ulterior de Direito Internacional geral da mesma natureza.”

Com relação às normas, ou seja, a obrigação dos Estados de cooperarem mutuamente e de negociar na conclusão dos tratados, é possível mencionar as consultorias do ACNUR com os Estados e com a sociedade civil, além dos atos firmados em que Estados se obrigam a implementar em seu ordenamento jurídico interno os princípios, as regras e os procedimentos adotados. Em nível de governo brasileiro, pode-se citar o acordo com o ACNUR para reassentamento de refugiados.

Sobre as regras, que concretizam as normas, são os tratados criados, podendo-se exemplificar os atos domésticos dos governos de incorporação dos tratados, como a lei ordinária federal brasileira 9474, de 22 de julho de 1997, que incorporou a Convenção de 1951 ao direito brasileiro.

Por último, os procedimentos de tomada de decisões são as decisões dos tribunais internacionais ou dos órgãos implementadores da Organizações 
Internacionais que são membros do regime, conforme prevê os estatutos, como as decisões dos comitês executivos ou a submissão ao Manual de procedimentos e critérios para a determinação da condição de refugiado. Em se tratando de refugiados, podem-se citar as decisões do comitê executivo do ACNUR.

Como visto, ao utilizar-se a definição de regime internacional de Krasner (1982), verifica-se que há um regime internacional dos refugiados, embora ele tenha sido criado em outro momento político, econômico e social global, no auge da Guerra Fria, que demandava atos e comportamentos diversos do atual. Com a mudança global e, particularmente, as alterações climáticas naturais ou provocadas pelo ser humano, novas necessidades surgiram e o regime precisou ser adaptado, particularmente em termos regionais.

Assim, a Convenção da Organização da Unidade Africana de 1969 (c/c a Decisão da Unidade Africana de 2004) e a Declaração de Cartagena de 1984 (c/c o Plano de Ação do México de 2004) expandiram a definição de refugiado da Convenção de 1951 e do Protocolo de 1967 para reconhecer como refugiado aqueles que estejam fugindo de guerras civis e violações aos direitos humanos, respectivamente. O regime americano também protege os deslocados internos, ou seja, aqueles que não ultrapassaram as fronteiras do Estado de origem.

Hodiernamente, o ACNUR, também alargando sua competência, busca proteger outros migrantes forçados, além dos refugiados e solicitantes de refúgio, como os asilados, os apátridas, os retornados e os deslocados internos. Ficam excluídos dessa proteção os palestinos, por receberem proteção de outro órgão da ONU, qual seja, a UNRWA, criada para proteger e apoiar os palestinos refugiados desde a criação do Estados de Israel (1947). Em termos numéricos, o ACNUR (2010) protege e apoia mais de 33 milhões de pessoas, conforme dados abaixo, sendo mais de 10 millhões de refugiados e mais de 14 milhões de deslocados internos:

\begin{tabular}{|l|l|}
\hline Refugiados & 10.549 .686 \\
\hline Solicitantes de Refúgio & 837.478 \\
\hline Refugiados Deslocados & 197.626 \\
\hline Deslocados Internos (DI) & 14.697 .804 \\
\hline DI Retornados & 2.923 .233 \\
\hline Apátridas & 3.463 .070 \\
\hline Outros & 1.255 .579 \\
\hline Total & $\mathbf{3 3 . 9 2 4 . 4 7 6}$ \\
\hline
\end{tabular}

Em relação aos deslocados internos, menos da metade deles está sob a proteção do ACNUR, que não possui recursos humanos nem financeiros suficientes 
para ampliar a proteção. Essas pessoas não podem ser consideradas refugiadas por não terem cruzado as fronteiras de seus Estados de origem, mas estão submetidas ao mesmo temor de perseguição dos refugiados. Infelizmente, não há um tratado vinculante sobre eles, embora o parágrafo segundo da introdução aos Princípios Orientadores relativos aos deslocados internos, em nível de ONU, de 1998, os defina como

\begin{abstract}
Pessoas ou grupos de pessoas que foram forçadas ou obrigadas a fugir ou a abandonar as suas casas ou os locais de residência habitual, de maneira súbita e imprevista, particularmente em consequência dos, ou com vistas a evitar os, efeitos de conflitos armados, situações de violência generalizada, violações massivas dos direitos humanos ou desastres naturais ou provocados pelo homem, e que não atravessaram uma fronteira nacional reconhecida internacionalmente.
\end{abstract}

Em nível regional latino americano, a Convenção Interamericana de Direitos Humanos, de 1969, prevê, em seu artigo 22 (7 e 8), o direito de movimento e de residência de qualquer pessoa, instituindo também o non refoulement. Coadunando-se com ela, a Declaração de Cartagena sobre Refugiados, de 1984, amplia, na conclusão (III) 3, a definição de refugiado, e a Declaração de San José sobre Refugiados e Deslocados, de 1994, adota, nas conclusões 10 e 15 a 17, a proteção aos migrantes econômicos (não forçados) e aos deslocados internos, respectivamente: O parágrafo 17 reconhece a importância de proteger os direitos humanos dos deslocados internos e o parágrafo 15 reconhece os desafios impostos pela nova situação de deslocamento humano na América Latina e no Caribe, incluindo, em particular, o aumento no deslocamento interno e na migração forçada devido a causas diferentes daquelas previstas na Declaração de Cartagena.

Ainda, a Declaração e o Plano de Ação do México, de 2004, também tratam dos deslocados internos. Por fim, a Declaração de Brasília sobre a Proteção de Refugiados e Apátridas nas Américas, de 2010, considera, no parágrafo 6, "a possibilidade de adotar mecanismos adequados de proteção nacional para lidar com novas situações não previstas pelos instrumentos internacionais relativos à proteção dos refugiados, dando a devida consideração às necessidades de proteção dos migrantes [...]." E, o parágrafo 10, reconhece "a importância de maiores alternativas para a migração regular e políticas migratórias que respeitem os direitos humanos dos migrantes, independente de sua condição migratória, [...].”

As vantagens desses instrumentos regionais é que eles encorajam uma abordagem integrada às soluções prescritas por outros instrumentos, como o retorno voluntário. Nesse sentido, o parágrafo 14 da Declaração de 1994 supracitada defende 
que

os esforços de reintegração e reabilitação devem estar ligado aos esforços de desenvolvimento sustentável a longo prazo, para aliviar e erradicar a pobreza extrema, satisfazer às necessidades humanas e fortalecer o respeito aos direitos humanos, com ao devida observância aos direitos civis, políticos, econômicos, sociais e culturais.

A Declaração de 1994 também afirma que

o problema dos deslocados internos, embora seja de responsabilidade fundamental dos Estados de nacionalidade deles, é, no entanto, motivo de preocupação para a comunidade internacional, pois é uma questão de direitos humanos que pode estar vinculada à prevenção das causas que geram os fluxos de refugiados,

ou, para os propósitos dessa pesquisa, que geram os deslocados ambientais. Consequentemente, políticas nacionais e internacionais devem existir em colaboração para lidar com esse dilema pendente e enfrentar os desafios que estão por vir.

O certo é que os refugiados e alguns deslocados internos estão protegidos internacionalmente por princípios, regras, normas e procedimentos de tomada de decisões, mas novos deslocados forçados, que são obrigados a deixar seus locais de origem por mudanças ambientais, provocadas ou não pelo ser humano, carecem de proteção internacional.

\section{OS DESLOCADOS AMBIENTAIS}

Quando os deslocados forçados ambientais cruzam as fronteiras juridicamente definidas de um Estado soberano, podem ser chamados de refugiados ambientais, embora não haja juridicamente um instrumento que os defina e os proteja, como afirma Myers (2005). Entretanto, se não houve cruzamento de fronteiras, eles são apenas deslocados ambientais. Assim, os deslocados internos ambientais são deslocados internos, pois o caráter involuntário do deslocamento é a chave para o reconhecimento como tal, pois eles são forçados a migrar depois que todos os meios de sobrevivência foram destruídos e seus direitos humanos básicos ficaram desprotegidos. Portanto, eles não podem ser considerados "migrantes motivados ambientalmente", que "podem migrar", conforme Renaud et al (2007, p. 29), mas apenas "migrantes forçados ambientalmente", que "devem migrar", isto é, eles não possuem a opção de decidir entre ficar ou partir, já que a sobrevivência está em risco.

Um exemplo são os deslocados forçados da seca, tanto do sertão Brasileiro 
quanto, no momento, na região do Chifre da África.Quanto ao Brasil, Albuquerque Júnior (1995, p. 111) afirma que ele é considerado um problema regional, embora nem sempre tenha sido assim, pois durante a "grande seca", entre 1877 e 1879 (que matou cerca de $13,9 \%$ da população cearense e $4 \%$ da população nordestina), ele se tornou um problema de impacto nacional, capturando o interesse público e provocando a intervenção estatal. Villa (2000, p. 13), que compara o número de mortos a um Holocausto, estima que cerca de três milhões de pessoas morreram vítimas de seca entre os séculos 19 e 20 no sertão nordestino brasileiro.

Quanto ao Chifre da África (Djibuti, Etiopia, Quênia e Somália), a pior seca dos últimos 60 anos assola a região (i.e. há dois anos não chove), cuja população já vem sofrendo há décadas por conflitos armados. Segundo o ACNUR (2011), cerca de 13 milhões de pessoas carecem de todo tipo de ajuda e sofrem, particularmente, por absoluta insegurança alimentar. Apenas a Somália já possui quase dois milhões de deslocados internos e refugiados resultantes dessa seca e da consequente epidemia de fome trazida com ela.

A seca, um dos fatores mais significantes para o deslocamento forçado ambiental, é considerada um desastre natural não repentino que pode ter trazido degradação gradual da terra e migração voluntária no passado. Mas, atualmente, tem forçado milhões de pessoas vulneráveis ao deslocamento, no sentido de que eles fogem de um local de origem insalubre e inóspito, sofrendo de estresse psicossocial, falta de renda, ruptura social e até, às vezes, sem documentos de identidade.

Ademais, os desastres ambientais, como a seca, ainda resultam em conflitos políticos, econômicos e sociais e violência (Homer-Dixon 2000 e 2003), ressaltando-se furtos, roubos, crimes de agressão e, no caso do Chifre da África, por exemplo, terrorismo, pirataria e tomada de reféns. Os conflitos e a violência são normalmente causados pela disputa pelos escassos recursos disponíveis. O Conselho de Segurança da ONU (ACNUR 2011) deverá se realizar uma reunião consultiva na Somália entre os dias 4 e 6 de setembro para traçar as estratégias colaborativas de paz na região.

Indubitavelmente, não importa se os deslocados ambientais cruzaram ou não as fronteiras de seus Estados de origem, o fato é que há milhões de pessoas deslocadas forçadamente por problemas de degradação ambiental (distúrbios, desastres, desenvolvimentou ou até resquícios de guerra), causados, lenta ou bruscamente, pela natureza, pelo ser humano ou, ainda, pela natureza, mas 
agravados ou induzidos pela ação humana. Assim, o deslocamento ambiental forçado é multicausal e associado à falta de condições sobrevivência, ou seja, segundo Schwartz (1993), os deslocados sofrem de desertificação ou outras alterações ambientais, violação dos direitos humanos e omissão estatal, tudo incluído.

$\mathrm{Na}$ falta de um regime internacional (princípios, normas, regras e procedimentos de tomada de decisões vinculantes) que os proteja em nível internacional, caso eles sejam considerados deslocados internos ou refugiados, uma solução, contudo, poderia ser uma abordagem integrada com os direitos humanos e com o direito humanitário, cujas normas vinculantes e instituições internacionais obrigariam os Estados a se responsabilizarem por este dilema multicausal, que combina o deslocamento involuntário com alterações ambientais, como a seca (i.e. processos lentos de desertificação), ainda que outros fatores estejam incluídos, como os sociais, econômicos e políticos, conforme defende Zetter (2008 e 2010). Nesse sentido, Castles (2002) enfatiza que as mudanças ambientais não podem ser tratadas isoladamente de outros fatores que minam a segurança humana, como pobreza, grau de apoio estatal à comunidade, acesso às oportunidades econômicas, eficácia dos processos de tomada de decisões e medidas de coesão social dentro e em torno dos grupos vulneráveis.

Portanto, a necessidade de reconhecimento jurídico pelos Estados e pela comunidade internacional é imprescindível não apenas para a proteção dos direitos humanos dos deslocados ambientais, que deve se coadunar com as obrigações internacionais dos Estados, mas também para a segurança humana e estatal, conforme afirmamZetteretal (2008 e 2009, p. 141-4) e Fletcheret al (2009).

Em nível de direito ambiental internacional, a Declaração Universal dos Direitos Humanos, de 1948, reza, implicitamente, em seu artigo 22, que todos possuem o direito a viver em um ambiente ecologicamente equilibrado. Ainda, é princípio jurídico ambiental (Princípio 13), conforme a Declaração do Rio, de 1992, que, se, por ação ou omissão, o governo causar dano ambiental que prejudique um indivíduo ou grupo de indivíduos, este dano é acionável por que cada um possui o direito a viver em um ambiente saudável. É o chamado direito de ser protegido contra dano ambiental que, especialmente no caso do Brasil, está previsto no artigo 225 da Constituição brasileira de 1988 (i.e. "todas as pessoas possuem o direito a um ambiente ecologicamente equilibrado e não apenas o poder público, mas também a coletividade, lato sensu, possui o dever de defendê-lo e preservá-lo para as gerações 
presentes e futuras.”).

Schwartz (1993) elenca, com base nos Princípios 1 e 10 da Declaração do Rio, de 1992, o direito à vida, a um ambiente saudável, à informação ambiental, à participação política nas decisões ambientais e à liberdade de expressão como formas de obter proteção internacional e nacional para vítimas de abuso ambiental. Entretanto, no caso de certas regiões, como o sertão brasileiro ou o chifre da África, a maioria dos deslocados é analfabeta e não possui educação ou informação de como agir contra os atos governamentais.

Na verdade, há recursos financeiros internacionais, há legislação em nível nacional e tratados internacionais em matéria ambiental em diversas regiões do mundo para lidar com a degradação do solo como resultado, por exemplo, da desertificação e da seca. O apoio errôneo, contudo, leva à ausência de proteção e à migração forçada, resultantes da institucionalização, ou seja, do rígido e poderoso sistema criado de cima para baixo para cuidar do ambiente local sem considerar os seres humanos como agentes de mudança adaptáveis, como é o caso daqueles ligados à terra e, por essa razão, conhecem melhor as necessidades locais e os tipos de apoio necessários para mitigar os problemas ambientais e adaptar suas vidas a este ambiente. Se, no mínimo, eles tivessem acesso à educação e à saúde, eles teriam recursos suficientes para se envolver em discussões públicas e lutar, ou seja, para permanecer na terra com condições de vida razoáveis e direitos humanos básicos protegidos por seus governos.

Infelizmente, Estados não desenvolvidos normalmente reagem apenas quando instigados por órgãos internacionais. A mobilização é necessária e uma resposta precisa alcançar os alvos dessa situação sem fim. Políticas públicas com medidas a curto, médio e longo prazo deveriam focar nesses deslocados internos antes, durante e após o deslocamento ocorrer, como forma de protegê-los e proteger suas terras, assim como obter segurança ambiental, humana (societária), estatal (política) e econômica, em níveis local, nacional e global (BUZAN 1998).

Em suma, se os Estados estiverem preocupados com suas próprias seguranças, e também com a segurança global, é hora de reconhecer juridicamente os deslocados forçados ambientais e adotar medidas para mitigar o impacto da degração de terra, particularmente dos desastres não repentinos, como secas, nas populações locais e promover meios de adaptar suas vidas ao ambiente local, ao facilitar o retorno daqueles deslocados e ao promover condições de vida daqueles que não 
puderam migrar, em conformidade com suas obrigações de direitos humanos e humanitário nos níveis nacional e internacional.

Devido à ausência de normas vinculantes e instituições internacionais para cobrar dos Estados, assim como devido às relações assimétricas de poder entre, de um lado os governos e os habitantes ricos e poderosos, e, de outro lado, os deslocados forçados ambientais pobres, não educados e destituídos de poder, uma solução pode ser o uso de atores não estatais para persuadir os governos a reconhecer que seus interesses na área de segurança estão ligados às sérias consequências trazidas pelos deslocados ambientais, como forma de superar os desastres ambientais, como as secas, as violações aos direitos humanos e a omissão dos Estados e, portanto, eles podem cooperar para superar o dilema por meio da persuasão via cruzamento de assuntos.

De acordo com Betts (2009, p. 4), a persuasão via cruzamento de assuntos são "as condições sob as quais um ator A pode persuadir um ator B de que um assunto $\mathrm{X}$ e um assunto $\mathrm{Y}$ são interligados de forma a induzir um ator B a agir em uma área X devido aos seus interesses no assunto Y.” Com relação aos deslocados ambientais, a persuasão via cruzamento de assuntos pode ser explicada como as condições sob as quais atores não estatais (i.e. ONG, a Academia e Organizações Internacionais) podem persuadir os Estados de que os deslocados ambientais e o tema de segurança são interligados, de forma a induzir os Estados a agirem para superar as situações prolongadas dos deslocados ambientais, com base nos interesses estatais em segurança. Portanto, para Betts, este tipo de persuasão é também um recurso de poder, pois Estados mais fracos podem usar da condicionalidade ou interligar assuntos para influenciar atores mais poderosos a cooperar com o fim de superar o dilema.

A implementação da persuasão via cruzamento de assuntos chama a atenção para o fato de que o mundo está cada vez mais complexo, particularmente com o fim da Guerra Fria. Assim, a proteção jurídica aos deslocados ambientais não pode mais ser vista isolada de outros campos políticos. Ao ligar o dilema dos deslocados forçados ambientais à questão de segurança, os Estados precisam adaptar normas, regras e instituições internacionais existentes às suas ordens jurídicas domésticas, mesmo na ausência de negociações formais em nível internacional, com o fim de implementar novas normas e políticas públicas necessárias para lidar com este dilema. 
Estas alterações podem ser realizadas por meio do alongamento do regime (regime stretching), definido por Betts (2010, p. 2) como "o grau pelo qual o escopo de um regime em nível nacional ou local assume tarefas adicionais ou complementares não prescritas em nível global." Isto significa que se as elites poderosas e os governos em nível local estiverem convencidos de que eles serão agraciados pela comunidade internacional por alongar o escopo das normas e instituições atuais referentes aos deslocados internos, com o fim de proteger os deslocados ambientais, então oalongamento ocorrerá. Isto pode ocorrer, segundo Betts (2010, p. 5-6), ao haver (re) negociamento de normas, adaptando-as à legislação local e nacional e implementando-as por meio de políticas públicas e práticas adequadas, de acordo com os interesses de cada governo.

Para Zetter (2010, p. 14), "é mais prudente adaptar normas e instrumentos de proteção aos migrantes já existentes e moldá-los para incorporar os desafios baseados em direitos emergentes postos pela mudança climática.” Quando normas ou instituições são adaptadas a novos problemas em nível de implementação, ou seja, no seio de instituições já existentes, isso é alongamento de regime. Para Betts (2010, p. 9),

este é um conceito particularmente importante no contexto de um mundo em que novos problemas e desafios estão surgindo, mas novas instituições formais são criadas mais lentamente, e há geralmente a necessidade de "velhas instituições globais" se adaptarem a "novos desafios nacionais."

Vários problemas, como os deslocados ambientais do sertão brasileiro ou do chifre da África, permanecem invisíveis até atingir os últimos graus de degradação humana e ambiental. Por essa razão, o alongamento de regimes pode incluir implementação de normas locais e adaptação de instituições. Isso significa que adaptação local pode ser obtida por meio da persuasão via cruzamento de assuntos, ao convencer os governos a interligar segurança à questão dos deslocados forçados ambientais; o que forneceria meios para a implementação de políticas públicas necessárias a mitigar a migração forçada como resultado de desastres ambientais, com o fim de promover adaptação, resiliência e sustentabilidade (Zetteret al 2008, p. 18-9). Ainda, a cooperação internacional é também necessária e deve ser buscada.

Algumas sugestões para lidar com esse dilema e buscar um solução duradoura para os deslocados forçados ambientais podem incluir o que segue: irrigação e reservatórios de água adequados a terra e ao clima locais, programas de micro créditos para pequenos agricultores familiares, formação de capital social (i.e. 
acesso aos recursos e formação de redes de confiança e cooperação), empoderamento feminino, acesso à educação (geral e direcionada às necessidades locais), acesso à saúde e, por fim, fiscalização internacional e nacional aos governos locais.

Outra sugestão seria rastrear pessoas deslocadas por questões ambientais e atrai-las ao retorno, oferecendo condições para reconstruir suas vidas no local de origem. Normalmente, pessoas deslocadas são ávidas para retornar, mas não possuem recursos financeiros (econômicos), sociais ou ambientais para isso.

Por fim, os deslocados geralmente não confiam em promessas governamentais, o que justifica a necessidade de cooperação internacional. Por exemplo, organizações internacionais e ONG podem ser estabelecidas na região para auxiliá-los localmente e mediar responsabilidades entre o governo, organizações (nacionais e internacionais) e deslocados forçados ambientais, sejam eles retornados ou não. Os instrumentos de direitos humanos podem também ser aplicados, na ausência de normas e instituições que lidem com o dilema dos deslocados associado à mudança climática.

\section{CONCLUSÕES}

O caso dos deslocados forçados ambientais é original no sentido de que eles são deslocados internos forçados devido às condições ambientais associadas à falta de proteção dos direitos humanos, sendo normalmente apenas reconhecidos como migrantes econômicos voluntários. Por essa razão, eles deveriam ser juridicamente reconhecidos, sob a proteção de um regime internacional, para que se tornassem visíveis à luz da comunidade internacional e recebessem proteção internacional.

Outra razão para a proteção jurídica, recebida com a criação de um regime, é a ligação entre o deslocamento e a segurança. Infelizmente, membros de instituições internacionais e governos ainda não estão cientes da interrelação entre segurança estatal e deslocamento ambiental forçado, como ocorre em diversas regiões do mundo, como Bangladesh, Brasil, Gana, Quênia, Vietnam, no momento, Chifre da África.

A persuasão por meio de cruzamento de assuntos pode convencer os governos e as instituições internacionais a alongar o regime, isto é, a adaptar normas e instituições internacionais que já existem para implementá-las em nível local, em conformidade com os instrumentos de direitos humanos. Em se tratanto de Brasil, 
um exemplo seria adaptar os Princípios Orientadores sobre Deslocamento Interno, de 1998, seu Programa Nacional de Direitos Humanos, de 2009, e seu Programa de Ação Nacional para Combater à Desertificação e Mitigar os Efetios da Seca, de 2004, e sua enorme quantidade de normas de direitos humanos e proteção ambiental, com o fim de proteger os deslocados ambientais e as terras sujeitas à degradação ambiental. Esta ação evitaria conflitos humanos e degradação da terra, traria desenvolvimento e faria o Brasil ser reconhecido como um exemplpo de boa fé nas relações internacionais.

Ao receber proteção jurídica, tanto os deslocados ambientais quanto os Estados e a comunidade internacional tirarão vantagem do desenvolvimento alcançado. Em parceria com organizações internacionais e ONG estabelecidas nas regiões afetadas, os governos e a população local dessas regiões serão capazes de lidar com a degradação ambiental trazida por desastres ou distúrbios ambientais, como secas intermitentes, e alcançar desenvolvimento, por meio de políticas adequadas de mitigação adaptadas às necessidades, à cultura e à terra locais. Assim, aqueles que se deslocaram estarão aptos a retornar e os que estavam preparando-se para o deslocamento serão, juntos com os primeiros, agentes de mudança local, ao perseguirem melhores condições de vida em uma região sustentável.

\section{REFERÊNCIAS}

ACNUR. Estatísticas. Disponível em: <http://www.acnur.org/t3/portugues/recursos/estatisticas >. Acesso em: o9 de agosto de 2011.

ACNUR. Chifre da África. Disponível em: $<$ http://www.onu.org.br/chifredaafrica $>$. Acesso em 16 de agosto de 2011.

ALBUQUERQUE JUNIOR, Durval M (1995). Palavras que Calcinam, Palavras que Dominam: a Invenção da Seca no Nordeste. Revista Brasileira de História,15 (28), p. 111-20.

BARROS-PLATIAU, Ana Flávia,VARELLA, Marcelo D. e SCHLEICHER, Rafael T. (2004). Meio ambiente e relações internacionais: perspectivas teóricas, respostas institucionais e novas dimensões de debate. RevistaBrasileira de

PolíticaInternacional 47 (2): 100-30.

BETTS, Alexander (2006). Conceptualising Interconnections in Global Governance: the case of refugee protection. Working Paper Series.RSC Working Paper 38.Oxford: RSC/QEH/IDC/University of Oxford.

BETTS, Alexander (2005). International Cooperation Between North and South to 
Enhance Refugee Protection in Regions of Origins .Working Paper Series. RSC Working Paper 25.Oxford: RSC/QEH/IDC/University of Oxford.

BULL, Hedley (2002). A Sociedade Anárquica: um estudo da ordem política mundial.Coleção Clássicos IPRI. [Trad. Sérgio Bath]. São Paulo: Imprensa Oficial do Estado, EDUnB e IPRI.

BUZAN, Barry. Security: a new framework for analysis. Boulder (EUA): Lynne Rienner Publishers. 1998.

CASTLES, Stephen (2002). Environmental change and forced migration : making sense of the debate. UNHCR.Evaluation and Policy Analysis Unit. Geneva: UNHCR.

COX, Robert (1996). Approaches to World Order. Cambridge: Cambridge University Press.

GOODWIN-GILL, Guy S (2011). The Right to Seek Asylum: Interception at Sea and the Principle of Non-Refoulement.Inaugural Lecture.Bruxelles: Palais des Académies, 16 February.

FLETCHER, Laurel et al (ed) (2009). Protecting People and the Planet: a proposal to address the Human Rights impacts of climate change policy. California: Centre for Law and Global Justice, International Human Rights Law Clinic \& Miller Institute for Global Challenges and the Law.

KEOHANE, Robert (1982). The Demand for International Regimes. International Organisation 36 (2): 325-55.

(1993). Institutional theory and the realistic change after the cold war.In BALWIN, David (ed.), Neorealism and Neoliberalism: The ContemporaryDebate.New York: Columbia University Press, NY. Pp. 3-25.

KRASNER, Stephen (1982). Structural Causes and Regime Consequences: Regimes as Intervening Variables. InternationalOrganisation 36 (2): 185-205.

GRIFFITHS, Martin (2004). 50 grandes estrategistas das Relações Internacionais. São Paulo: Contexto.

HASENCLEVER, Andreas; MAYER, Peter e RITTBERGER, Volker (1997). Theories of International Regimes. Cambridge: Cambridge University Press.

HOMER-DIXON, Thomas (2003). Debating Violent Environments.Violent Environments. 9, p. 89-92.

(2000). Scarcity and Conflict. Forum for Applied Research and Public Policy. 15 (1) p. 28-36.

MYERS, Norman (2005). Environmental Refugees: an emergent security

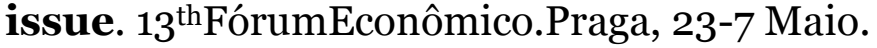

RENAUD, Fabriceet al (2007). Control, adapt or flee : how to face environmental migration?. Bonn: UNU and Institute for Environment and 
Human Security.

SCHWARTZ, Michelle Leighton (1993). International Legal Protection for Victims of Environmental Abuse.Yale JournalofInternational Law. 18, pp. 355-87.

VILLA, Marco Antônio (2000). Vida e Morte no Sertão: história das secas no Nordeste nos Séculos XIX e XX. São Paulo: Ática.

WALLERSTEIN, Imanuel (1984). Tipologia das Crises no Sistema

Mundial.Essex: Universidade das Nações Unidas, mimeo.

Mundo. Petrópolis: Vozes.

(2002). Após o Liberalismo - Em Busca da Reconstrução do

YOUNG, Oran (1982). Regime Dynamics: the Rise and Fall of International Regimes. International Organisation, 36 (2): 277-97.

ZETTER, Roger; MORRIS, Tim; BOANO, Camillo (2008). Environmentally Displaced People: Understanding the Linkages between Environmental change, livelihoods and forced migration.Forced Migration Policy Briefing 1.Oxford: RSC/ODID/University of Oxford.

ZETTER, Roger (2009). The role of legal and normative frameworks for the protection of environmentally displaced people. In: LACZKO, Frank and AGHAZARM, Christine (2009). Migration, environment and climate change: assessing the evidence. IOM, UNU and Institute for Environment and Human Security, Geneva.

(2010). Protecting environmentally displaced people:

developing the capacity of legal and normative frameworks. Oxford: RSC/ Universityof Oxford. Disponível em: <http://www.rsc.ox.ac.uk/pdfs/Zetter\%20EnvDispRep\%2015022011.pdf > . Acesso em 26 de Junho de 2011. 